\title{
SUB RUANG TUTUP TOPOLOGI HASIL KALI RUANG METRIK KERUCUT
}

\author{
Badrulfalah, Iin Irianingsih \\ Departemen Matematika, FMIPA Universitas Padjajaran, Bandung \\ e-mail : badrulfalah@gmail.com,iin_mtk@yahoo.com \\ DOI : 10.24036/eksakta/vol19-iss01/128
}

\begin{abstract}
Sebuah sifat topologi selain dapat dimiliki oleh suatu ruang topologi juga dapat dimiliki oleh subruang dari ruang topologi tersebut. Pada makalah ini akan dibahas tentang aksioma keterhitungan pertama pada topologi hasil kali ruang metrik kerucut, khususnya pada subruang tutup. Pembahasan dilakukan dengan menunjukkan bahwa setiap elemen dari setiap subruang tutup dari topologi hasil kali dua ruang metrik kerucut memiliki basis lokal terhitung. Hasilnya adalah setiap subruang tutup dari topologi hasil kali ruang metrik kerucut juga memenuhi aksioma keterhitungan pertama. Dengan kata lain keterhitungan pertama bersifat hereditas lemah.
\end{abstract}

Keywords : Aksioma keterhitungan pertama, subruang tutup,basis lokal, hereditas lemah

\section{PENDAHULUAN}

Ruang metrik kerucut merupakan perluasan dari ruang metrik biasa, didefinisikan oleh Huang \& Zhang pada [3]. Setiap metrik menginduksi sebuah topologi metrik, begitupun dengan metrik kerucut. Topologi yang diinduksi oleh metrik kerucut disebut topologi metrik kerucut. Topologi memiliki banyak aspek kajian, di antaranya adalah sifat topologi, hereditas dan hereditas lemah. Ada banyak sifat topologi, salah satunya adalah aksioma keterhitungan pertama. Turkoglu \& Abuloha pada [7] telah membuktikan bahwa setiap ruang metrik kerucut adalah ruang hitung pertama. Menggunakan hasil pada [2] Badrulfalah, Khafsah J, dan Iin Irianingsih pada [1] telah melakukan penelitian permulaan tentang aksioma keterhitungan pertama pada topologi hasil kali dua ruang metrik kerucut. Hasilnya adalah aksioma keterhitungan pertama selain berlaku pada topologi hasil kali dua ruang metrik kerucut juga berlaku pada setiap subruangnya. Dengan perkataan lain bahwa aksioma keterhitungan pertama pada topologi hasil kali dua ruang metrik kerucut bersifat hereditas.

Mengingat tidak setiap sifat yg dimiliki oleh suatu ruang topologi juga dapat dimiliki oleh subruang tutupnya, sebagai kelanjutan dari penelitian yang diperoleh pada [1] maka pada penelitian ini dibahas keberlakuan aksioma keterhitungan pertama pada subruang tutup dari ruang topologi hasil kali dua ruang metrik kerucut. Tujuan dari penelitian ini adalah membuktikan bahwa aksioma keterhitungan pertama pada topologi hasil kali dua ruang metrik kerucut merupakan hereditas lemah.

\section{METODE PENELITIAN}

Untuk membuktikan keterhitungan pertama pada topologi hasil kali dua ruang metrik kerucut merupakan sifat hereditas lemah dilakukan dengan menunjukkan bahwa setiap subruang tutup dari ruang tersebut 
juga terhitung pertama yaitu setiap elemen dari setiap subruang tutupnya memiliki basis lokal terhitung.

\section{HASIL DAN PEMBAHASAN}

\section{Beberapa Teori Dasar}

Beberapa definisi dan lemma terkait diberikan sebagai berikut.

Pada Definisi 1.1 diberikan definisi ruang metrik.

Definisi 1.1: Misal $X \neq \emptyset$ dan $d: X \times X \rightarrow \mathbb{R}$ memenuhi:

$\left(d_{1}\right) . \quad 0 \leq d(x, y), \forall x, y \in X \quad$ dan $d(x, y)=0$ jika dan hanya jika $x=y$;

$\left(d_{2}\right) . \quad d(x, y)=d(y, x), \forall x, y \in X$

$\left(d_{3}\right) \quad d(x, y) \leq d(x, z)+d(z, y)$.

Maka $\boldsymbol{d}$ disebut metrik pada $X$ dan $(X, d)$ disebut Ruang metrik. [4]

Setiap metrik menginduksi topologi.

Pada Definisi 1.2 diberikan definisi subruang topologi.

Definisi 1.2 : Misal $(X, \tau)$ ruang topologi dan $\operatorname{dan} A \neq \emptyset \subseteq X . \tau_{A}=\{G \cap A \mid G \in \tau\}$ disebut topologi relatif pada $A$ dan buka $\left(A, \tau_{A}\right)$ disebut subruang $(X, \tau) .[4]$

Lemma 1.3 : Misal $(X, \tau)$ ruang topologi dan misal $\left(A, \tau_{A}\right)$ subruang dari $(X, \tau) . A$ tutup di $X \quad$ jika dan hanya jika pemetaan inklusi $i: A \subset X$ adalah pemetaan tutup.[6]

Lemma 1.4 : Misal $(X, d)$ ruang metrik dan $A \subseteq X . G_{A}$ buka di $(A, d)$ jika dan hanya jika terdapat $G_{X}$ buka di $(X, d)$ sedemikian sehingga $G_{A}=A \cap G_{X} \cdot[2]$

Pada Definisi 1.5 berikut diberikan definisi basis lokal.

Definisi 1.5: Misal $(X, \tau)$ ruang topologi $p \in X$. Kelas himpunan buka $\beta_{p}=\{B$ bukal $p \in B\}$ dinamakan basis lokal pada $p$ jika $\forall G$ buka dengan $p \in G$ terdapat $G_{p} \in \beta_{p} \quad$ sedemikian sehingga $p \in G_{p} \subset G$.[4]

Pada Definisi 1.6 diberikan definisi hereditas.

Definisi 1.6: Misal $(X, \tau)$ ruang topologi dan misal $P$ adalah sebuah sifat pada ruang topologi $(X, \tau) . P$ dikatakan hereditas jika setiap subruang dari $(X, \tau)$ juga memiliki sifat $P$.[4]

Lemma 1.7: Jika $A_{1}, A_{2}$ terhitung maka $A_{1} \times A_{2}$ terhitung. [4]

Pada Definisi 1.8 diberikan definisi ruang terhitung pertama.

Definisi 1.8: Misal $(X, \tau)$ ruang topologi. $X$ disebut ruang terhitung pertama jika setiap $p \in X$ memiliki basis lokal terhitung. [4]

Lemma 1.9 : Misal $\left(A, \tau_{A}\right)$ subruang $(X, \tau)$ dan $p \in A$. Jika $\beta_{p}$ basis lokal pada $p \in X$ maka $\beta_{p}^{*}=\beta_{p} \cap A$ basis lokal pada $p \in A$. [4]

Pada Definisi 1.10 diberikan definisi kerucut.

Definisi 1.10: $E$ ruang Banach Real misal $P \subseteq E$. Himpunan $P$ disebut kerucut jika :

i. $P \neq \emptyset$ tutup, dan $P \neq\{0\}$.

ii. Jika $a, b \geq 0$ dan Jika $x, y \in P$, maka ; $a x+b y \in P$

iii. $P \cap(-P)=\{0\} .[5]$

Selanjutnya melalui perluasan metrik, diperoleh definisi ruang metrik kerucut yang didefinisikan oleh Huang dan Zhang. Definisi ruang metrik kerucut diberikan pada Definisi 1.11 berikut.

Definisi 1.11: Misal $X \neq \emptyset$ dan $E$ ruang Banach Real yang dilengkapi dengan pengurutan parsial $\leq$ terhadap kerucut $P \subseteq E$. Jika $d: X \times X \rightarrow E$ memenuhi: 
$\left(d_{1}\right) . \quad 0 \leq d(x, y), \forall x, y \in X \quad$ dan $d(x, y)=0$ jika dan hanya jika $x=y$;

$\left(d_{2}\right) . d(x, y)=d(y, x), \forall x, y \in X$

$\left(d_{3}\right) \quad d(x, y) \leq d(x, z)+d(z, y)$.

$\forall x, y, z \in X$

Maka $\boldsymbol{d}$ disebut metrik kerucut pada $X$ dan $(X, d)$ disebut ruang metrik kerucut. [3]

Pada Definisi 1.12 berikut diberikan definisi topologi metrik kerucut.

Definisi 1.12 : Misal $(X, d)$ ruang metrik kerucut. Topologi $\tau$ pada $X$ yang dibangkitkan oleh sphere buka di $X$ dinamakan topologi metrik kerucut atau topologi yang diinduksi oleh metrik kerucut d.

Untuk selanjutya jika disebutkan $(X, d)$ ruang metrik kerucut maka selalu diasumsikan bahwa $E$ dan $P$ masingmasing sebagai ruang Banach real dan kerucut dari ruang terkait.

Dengan cara serupa pada pendefinisian himpunan buka di ruang metrik, pada Definisi 1.13 berikut diberikan definisi himpunan buka di ruang metrik kerucut.

Definisi 1.13: Misal $\left(x_{1}, d_{1}\right)$ ruang metrik kerucut. $W_{1}$ dikatakan buka di $X_{1}$ jika untuk setiap $p_{1} \in W_{1}$ terdapat $S\left(p_{1}, \delta_{1}\right)$ dengan $\delta_{1} \in E_{1}$ sedemikian hingga $S\left(p_{1}, \delta_{1}\right) \subseteq W_{1}$.

Lemma 1.14: Setiap ruang metrik kerucut adalah ruang terhitung pertama.[7]

Definisi 1.15: Misal $\left(X_{1}, d_{1}\right)$ dan $\left(X_{2}, d_{2}\right)$ ruang metrik kerucut hasil kali $X_{1}$ dan $X_{2}$, dinotasikan $X_{1} \times X_{2}$ adalah ruang metrik kerucut dengan metrik kerucut $d$, dinotasikan $\left(X_{1} \times X_{2}, d\right)$.

Definisi 1.16: Misal $\left(X_{1} \times X_{2}, d\right)$ ruang metrik kerucut. $W \subseteq X_{1} \times X_{2}$ adalah buka jika untuk setiap $p=\left(p_{1}, p_{2}\right) \in W$ terdapat $W_{1}$ dan $W_{2}$ masing-masing buka di $X_{1}$ dan $X_{2}$ dan sphere buka $S\left(p_{1}, \delta_{1}\right)$ dan $S\left(p_{2}, \delta_{2}\right)$ dengan $\delta_{1}, \delta_{2} \in E$ dan $p_{1} \in W_{1}$ dan $p_{2} \in W_{2} \quad$ sedemikian sehingga $\left(p_{1}, p_{2}\right) \in S\left(p_{1}, \delta_{1}\right) \times S\left(p_{2}, \delta_{2}\right) \subseteq W_{1} \times$ $W_{2} \subseteq W$

Pada Lemma 1.17 dan Lemma 1.18 diberikan sifat aksioma keterhitungan pertama masing-masing pada topologi hasil kali dan subruangnya. Keduanya merupakan hasil penelitian pada[1].

Lemma 1.17: Misal $\left(X_{1} \times X_{2}, d\right)$ ruang metrik kerucut maka $X_{1} \times X_{2}$ adalah ruang terhitung pertama.[1]

Lemma 1.18: Keterhitungan pertama adalah sifat hereditas pada ruang topologi kerucut $X_{1} \times X_{2} \cdot[1]$

\section{Subruang Tutup dari Ruang Topologi Kerucut.}

Pada [1] Badrulfalah, Khafsah J., dan Iin Irianingsih telah membuktikan bahwa aksioma keterhitungan pertama pada topologi hasil kali dua ruang metrik kerucut $X_{1} \times X_{2}$ bersifat hereditas. Dalam paper ini diberikan pembuktian keterhitungan pertama subruang tutup pada ruang topologi kerucut $X_{1} \times X_{2}$. Untuk itu terlebih dahulu diberikan definisi hereditas lemah pada Definisi 2.1 berikut.

Definisi 2.1: Misal $(X, \tau)$ ruang topologi dan $P$ sebuah sifat pada $(X, \tau)$. $P$ dikatakan hereditas lemah jika setiap subruang tutup dari $(X, \tau)$ juga memiliki sifat $P$.[6]

Selanjutnya pada Teorema 2.2 berikut diberikan pembuktian keberlakuan aksioma keterhitungan pertama pada setiap subruang tutup dari ruang topologi hasil kali dua ruang metrik kerucut $X_{1} \times X_{2}$. 
Teorema 2.2: Keterhitungan pertama adalah sifat hereditas lemah topologi hasil kali dua ruang metrik kerucut $X_{1} \times X_{2}$.

Bukti: Misal $\left(A, \tau_{A}\right)$ subruang tutup sebarang dari $X_{1} \times X_{2}$. Akan ditunjukkan $\left(A, \tau_{A}\right)$ ruang terhitung pertama.

Ambil $p \in A$ sebarang. Karena $A \subseteq X_{1} \times X_{2}$ maka $p \in X_{1} \times X_{2}$. Perdefinisi maka $p=\left(p_{1}, p_{2}\right)$ untuk suatu $p_{1} \in X_{1}$ dan $p_{2} \in X_{2}$. Karena $X_{1}$ ruang metrik kerucut, menurut Lemma 1.14 maka $X_{1}$ ruang terhitung pertama. Berdasarkan Definisi 1.8 maka

terdapat

$\beta_{p_{1}}=\left\{s\left(p_{1}, \delta_{1}\left(\frac{c}{n}\right)\right) \mid n \in \mathbb{N}\right\}$ basis lokal terhitung pada $p_{1}$ dengan $c \gg 0, c \in E$.

Karena $X_{2}$ ruang metrik kerucut, menurut Lemma 1.14 maka $X_{2}$ ruang terhitung pertama. Berdasarkan Definisi 1.8 maka terdapat $\quad \beta_{p_{1}}=\left\{s\left(p_{2}, \delta_{2}\left(\frac{c}{m}\right)\right) \mid m \in \mathbb{N}\right\}$ basis lokal terhitung pada $p_{2}$ dengan $c \gg 0, c \in E$.

Definisikan $\beta_{p}=\beta_{p_{1}} \times \beta_{p_{2}}$.

Akan ditunjukkan bahwa $\beta_{p}$ adalah basis lokal terhitung pada $p$.

Misal $G \subset X_{1} \times X_{2}$ buka dengan $p \in G$ maka $G=G_{1} \times G_{2}$ untuk suatu $G_{1}$ buka $X_{1}$ dan $G_{2}$ buka di $X_{2}$ dengan $p_{1} \in G_{1}$ dan $p_{2} \in G_{2}$. Karena $\beta_{p_{1}}$ basis lokal pada $p_{1}$ berdasarkan Definisi 1.5, maka terdapat $B_{\delta_{1}\left(\frac{c}{n_{0}}\right)}\left(p_{1}\right)=S\left(p_{1}, \delta_{1}\left(\frac{c}{n_{0}}\right)\right) \in \beta_{p_{1}}$

sedemikian sehingga

$B_{\delta_{1}\left(\frac{c}{n_{0}}\right)}\left(p_{1}\right)=S\left(p_{1}, \delta_{1}\left(\frac{c}{n_{0}}\right)\right) \subset G_{1}$.
Karena Karena $\beta_{p_{3}}$ basis lokal $p_{2}$, berdasarkan Definisi 1.5 maka terdapat $B_{\delta_{3}\left(\frac{c}{m_{0}}\right)}\left(p_{2}\right)=S\left(p_{2}, \delta_{2}\left(\frac{c}{m_{0}}\right)\right) \in \beta_{p_{3}}$ sedemikian sehingga

$B_{\delta_{2}\left(\frac{c}{m_{0}}\right)}\left(p_{2}\right)=S\left(p_{2}, \delta_{2}\left(\frac{c}{m_{0}}\right)\right) \subset G_{2}$.

Pilih $m=\operatorname{maks}\left(n_{0}, m_{0}\right)$ maka

$B_{\delta\left(\frac{c}{m}\right)}(p)=S\left(p, \delta\left(\frac{c}{m}\right)\right)=S\left(p_{1}, \delta\left(\frac{c}{m}\right)\right) \times$ $s\left(p_{2}, \delta\left(\frac{c}{m}\right)\right) \subset G_{1} \times G_{2}=G$

Berdasarkan Definisi 1.5 maka

$\beta_{p}=\beta_{p_{1}} \times \beta_{p_{z}}$ adalah basis lokal pada $p$ di $X_{1} \times X_{2}$.

Karena $\beta_{p_{1}}$ dan $\beta_{p_{3}}$ terhitung, berdasarkan Lemma 1.7 maka $\beta_{p}$ terhitung.

Selanjutnya misalkan $G_{A}=G \cap A$ maka $G_{A}=\left(G_{1} \cap A_{1}\right) \times\left(G_{2} \cap A_{2}\right)$. Dalam hal ini, berdasarkan Lemma 1.4 maka $G_{1} \cap A_{1}$ dan $G_{2} \cap A_{2}$ masing-masing buka di $A_{1}$ dan $A_{2}$. Oleh karena itu berdasarkan Definisi 1.16, maka $G_{A}$ buka di $A$. Dengan kata lain $G_{A}=\left(G_{1} \cap A_{1}\right) \times\left(G_{2} \cap A_{2}\right) \in \tau_{A}$.

Karena $p \in A$ dan $p \in G$ maka $p \in G_{A}$ sehingga $\quad p_{1} \in G_{1} \cap A_{1} \quad$ dan $p_{2} \in G_{2} \cap A_{2}$.

Definisikan $\quad \beta_{p_{1}}{ }^{*}=\beta_{p_{1}} \cap A_{1} \quad$ dan $\beta_{p_{2}}{ }^{*}=\beta_{p_{2}} \cap A_{2}$. Berdasarkan Lemma 1.9 maka $\beta_{p_{1}}^{*}$ dan $\beta_{p_{3}}^{*}$ masing-masing basis lokal pada $p_{1} \in A_{1}$ dan $p_{2} \in A_{2}$.

Definisikan

$$
\begin{aligned}
& \beta_{p}^{*}=\beta_{p} \cap A=\beta_{p_{1}} \times \beta_{p_{z}} \cap A \\
&=\beta_{p_{1}} \cap A_{1} \times \beta_{p_{z}} \cap A_{2}
\end{aligned}
$$

Karena $\beta_{p}$ adalah basis lokal pada $p$ di $X_{1} \times X_{2}$, berdasarkan Lemma 1.9 maka $\beta_{p}{ }^{*}$ 
adalah basis lokal $p$ di $A$. Karena $\beta_{p}$ terhitung maka $\beta_{p}{ }^{*}$ terhitung. Dengan demikian setiap elemen dari setiap subruang tutup $\left(A, \tau_{A}\right)$ memiliki basis lokal terhitung. Berdasarkan Definisi 1.8 maka $\left(A, \tau_{A}\right)$ adalah subruang tutup terhitung pertama. Ini berarti setiap subruang tutup dari ruang topologi hasil kali dua ruang metrik kerucut memenuhi aksioma keterhitungan pertama. Berdasarkan Definisi 2.1 maka keterhitungan pertama pada ruang topologi hasil kali ruang metrik kerucut adalah hereditas lemah.

\section{KESIMPULAN}

Berdasarkan hasil pembahasan dapat disimpulkan bahwa setiap elemen dari setiap subruang tutup dari ruang topologi hasil kali dua ruang metrik kerucut memiliki basis lokal terhitung. Ini berarti keterhitungan pertama pada topologi hasil kali dua ruang metrik kerucut merupakan bersifat hereditas lemah.

\section{DAFTAR PUSTAKA}

[1] Badrulfalah, Khafsah J., Iin I. 2017. Sifat Sub Ruang Topologi Hasil Kali Ruang Metrik Kerucut. Jurnal Euclid, pISSN 2355-1712, e-ISSN 2541-4453, Vol. 4 No. 2, pp. 704-709.

[2] Goldberg, Richard. R. 1976. Method of Real Analysis, second editions. John Wiley and Sons, Inc.

[3] Huang, L.G; Zhang, X. 2007. Cone Metric Spaces and Fixed Point Theorems of Co ntractive Mapping. Journal Of Mathematical Analysis And Applications 332, No. 2, pp.1467-1468.

[4] Lipschutz, Seymour. 1981. Theory and Problem General Topology. McGrawHill, Singapore.

[5] Sabetghadam, F.; Masiha. 2009. Some Couple Fixed Point Theorems in Cone Metric Spaces., Hindawi Publishing
Corporations, Fixed Point Theory and Applications, No.125426.

[6] Sze-Tsen Hu. 1964. Element of General topology. Holden-Day, Inc.

[7] Turkoglu, D.; Abuloha, M.,. 2010. Cone Metric Spaces and Fixed Point Theorems in Diametrically Contractive Mapping, Acta Mathematica sinica 26, No. 3, pp: 489-496. 